\title{
Faktor yang Memengaruhi Luaran Kualitas Hidup Anak dengan Hidrosefalus Setelah Pemasangan Shunt Ventrikulo-Peritoneal di Rumah Sakit Umum dr. Mohammad Hoesin Palembang
}

Erni Desmita, ${ }^{1}$ Masayu Rita Dewi, ${ }^{1}$ Syarif Darwin,,${ }^{1}$ Irfannuddin, ${ }^{2}$ Trijoso Permono, ${ }^{3}$ Raden Muhammad Indra ${ }^{1}$

${ }^{1}$ Departemen Kesehatan Anak, ${ }^{2}$ Unit Penelitian Fakultas Kedokteran, ${ }^{3}$ Departemen Bedah RSU dr. Mohammad Hoesin/Fakultas Kedokteran Universitas Sriwijaya, Palembang

Latar belakang. Anak hidrosefalus dengan VP shunt dapat mengalami penurunan kualitas hidup (QoL) akibat berbagai faktor yang hingga kini belum banyak diteliti.

Tujuan. Menilai luaran QoL anak hidrosefalus dengan VP shunt dan faktor yang memengaruhinya.

Metode. Anak berusia 5-18 tahun dengan hidrosefalus yang dipasang VP shunt tahun 2010-2015 diidentifikasi melalui rekam medis. Orangtua kemudian diwawancarai dengan panduan kuesioner HOQ (hydrocephalus outcome questionnaire). Hasil meliputi skor QoL pada aspek fisik, kognitif, dan keseluruhan. Skor 0 menunjukkan luaran terburuk dan skor 1 terbaik. Dilakukan analisis perbedaan skor berdasarkan faktor risiko (usia saat pemasangan, etiologi, adanya kejang dan komplikasi shunt) dan analisis kategorik berdasarkan pencapaian skor standar penelitian terdahulu $(0,69)$.

Hasil. Terdapat 95 anak yang diidentifikasi, 18 meninggal dan 46 dengan data tidak lengkap sehingga terdapat 31 anak yang dianalisis. Skor HOQ yang didapatkan, yaitu fisik $0,75 \pm 0,27$, sosial-emosional $0,78 \pm 0,22$, kognitif $0,66 \pm 0,31$, dan keseluruhan $0,73 \pm 0,25$. Skor HOQ keseluruhan lebih rendah pada anak dengan komplikasi. Kejang (RR 2,52) dan komplikasi shunt (RR 4,85) berhubungan dengan luaran buruk. Analisis multivariat menunjukkan hanya komplikasi yang berhubungan dengan QoL buruk (adjusted OR 15,11).

Kesimpulan. Luaran QoL ditemukan lebih baik dibandingkan penelitian sebelumnya. Kejang dan komplikasi shunt dapat berpengaruh negatif terhadap luaran QoL anak hidrosefalus dengan VP shunt. Sari Pediatri 2022;23(5):299-305

Kata kunci: anak, hidrosefalus, VP shunt, kualitas hidup, hydrocephalus outcome questionnaire

\section{Factors Associated with Quality of Life Outcomes in Children with Hydrocephalus After Ventriculo-Peritoneal Shunt Surgery at dr. Mohammad Hoesin General Hospital Palembang}

Erni Desmita, ${ }^{1}$ Masayu Rita Dewi, ${ }^{1}$ Syarif Darwin, ${ }^{1}$ Irfannuddin, ${ }^{2}$ Trijoso Permono, ${ }^{3}$ Raden Muhammad Indra ${ }^{1}$

Background. Hydrocephalus is a pediatric neurosurgical condition that may negatively impact the quality of life (QoL).

Objective. To assess the QoL outcomes and identify factors associated with poor QoL in children with hydrocephalus after VP shunt surgery at the dr.Mohammad Hoesin Hospital.

Methods. Children aged 5-18 years with hydrocephalus who had VP shunt surgery between 2010-2015 were identified. Parents were interviewed using the HOQ questionnaire. Results consisted of physical, socio-emotional, cognitive, and overall scores, which scales between 0 (worst) and 1(best). Data were analyzed as differences between risk factors (age at shunt placement, etiology, seizure, and complications) and categorically based on achievement of favorable overall score $(>0.69)$.

Results. Ninety-five children were eligible, 18 died and 46 had incomplete records, thus 31 children were included. The HOQ scores were physical $0.75 \pm 0.27$, social-emotional $0.78 \pm 0.22$, cognitive $0.66 \pm 0.31$, and overall $0.73 \pm 0.25$. Shunt complication was associated with lower HOQ scores. Seizure and complication were associated with failure to achieve an overall score $>0.69$ (RR 2.52 and 4.85 respectively). Only the presence of complication was found to be independently associated with poor QoL (adjusted OR 15.11).

Conclusion. Better QoL outcomes were found compared to previous studies. Seizure and shunt complications negatively affect QoL outcomes in children after VP shunt surgery. Sari Pediatri 2022;23(5):299-305

Keywords: children, hydrocephalus, VP shunt, quality of life, hydrocephalus outcome questionnaire

Alamat korespondensi: Masayu Rita Dewi, Departemen Kesehatan Anak RSU dr. Mohammad Hoesin Palembang, Jalan Jenderal Sudirman KM 3,5 Palembang, Sumatera Selatan, Indonesia. Email: neuro.anak.rsmh@gmail.com 
Erni Desmita dkk: Faktor yang memengaruhi luaran kualitas hidup anak dengan hidrosefalus setelah pemasangan VP shunt

$\mathrm{H}$ idrosefalus adalah kondisi dengan cairan serebrospinal berlebihan dan pembesaran ventrikel otak, yang dapat menyebabkan peninggian tekanan intrakranial dengan angka mortalitas dan kecacatan tinggi. ${ }^{1}$ Pemasangan shunt ventrikulo-peritoneal (VP shunt) merupakan prosedur tersering yang dilakukan untuk menangani hidrosefalus pada anak. Meski VP shunt dapat menurunkan mortalitas secara bermakna, angka kegagalan jangka panjangnya tinggi sehingga sering membutuhkan operasi ulang. ${ }^{2}$

Anak dengan hidrosefalus berisiko mengalami gangguan fungsi motorik dan kognitif, meliputi memori, fungsi eksekutif, kemampuan visuo-spatial, perhatian dan kemampuan bicara. ${ }^{3,4}$ Gangguan ini dapat diperberat oleh masalah medis yang dapat terjadi akibat kegagalan shunt sehingga terjadi penurunan kualitas hidup yang bermakna. Anak-anak di negara berkembang juga menghadapi masalah tambahan akibat terbatasnya pelayanan medis dan rehabilitasi terbatas, serta dukungan untuk anak berkebutuhan khusus yang masih suboptimal.

Kualitas hidup (QoL) anak hidrosefalus yang telah dipasang VP shunt di Indonesia belum banyak diteliti. Terdapat berbagai perangkat yang dapat digunakan untuk menilai QoL pada anak dengan hidrosefalus. Kulkarni dkk mengembangkan hydrocephalus outcome questionnaire (HOQ) yang dapat digunakan untuk menilai berbagai ukuran-ukuran QoL meliputi kesehatan fisik, kognitif dan sosial-emosional. Kuesioner ini telah divalidasi penelitian-penelitian setelahnya dan dapat digunakan dengan mudah dan cepat, serta memiliki korelasi yang kuat dengan berbagai pemeriksaan neuropsikologis termasuk uji intelegensi Wechsler.,

Berbagai faktor dapat memengaruhi kualitas hidup anak hidrosefalus dengan VP shunt. Usia yang lebih muda saat pemasangan, operasi ulang untuk revisi, dan adanya kejang dapat berdampak negatif terhadap kualitas hidup. ${ }^{5,7-9}$ Penelitian-penelitian lain juga menemukan bahwa etiologi hidrosefalus tertentu seperti perdarahan dan infeksi akan menyebabkan luaran kualitas hidup lebih buruk. ${ }^{10,11}$ Penelitian ini bertujuan untuk menentukan luaran kualitas hidup anak berusia lebih dari lima tahun dengan hidrosefalus yang telah terpasang VP shunt dan mengetahui pengaruh berbagai faktor meliputi usia saat operasi, etiologi hidrosefalus, adanya kejang dan komplikasi shunt terhadap kualitas hidup.

\section{Metode}

Anak berusia 5-18 tahun yang dioperasi untuk pemasangan VP shunt di RSU dr. Mohammad Hoesin periode Januari 2010 sampai Desember 2015 diidentifikasi melalui penelusuran rekam medis. Pasien diikutkan dalam penelitian apabila VP shunt telah terpasang setidaknya selama 6 bulan.

Selanjutnya, orang tua dihubungi dan dimintakan persetujuan setelah penjelasan. Kasus-kasus hidrosefalus yang disertai anomali struktural kompleks, seperti spina bifida, schizencephaly, megalencephaly atau sindrom Dandy Walker, pasien dengan rekam medis tidak lengkap atau tidak dapat dihubungi dieksklusi dari penelitian. Penilaian luaran kualitas hidup (QoL) dilakukan dengan wawancara orang tua menggunakan panduan angket HOQ yang terdiri dari 51 item. Hasil penilaian berupa skor fisik, sosial-emosional, kognitif, dan skor keseluruhan. Skor 0 menunjukkan hasil paling buruk, sedangkan skor 1 menunjukkan hasil paling baik. Hasil penilaian QoL dianalisis berdasarkan faktor-faktor risiko, yaitu usia saat diagnosis, usia saat pemasangan shunt, lama waktu antara diagnosis dan pemasangan shunt, jenis hidrosefalus (komunikans atau non-komunikans), adanya kejang setelah pemasangan shunt, dan adanya komplikasi shunt.

Data mengenai faktor risiko didapatkan dari penelusuran rekam medis. Komplikasi shunt merupakan semua kondisi yang membutuhkan revisi shunt, misalnya infeksi, penyumbatan atau malposisi. Perbedaan skor antar kelompok faktor risiko dianalisis dengan student's t-test atau Mann Whitney $U$ test. Korelasi antar variabel kontinyu (usia saat diagnosis dan saat pemasangan shunt) dan skor HOQ dianalisis dengan analisis korelasi Pearson atau Spearman. Dilakukan juga analisis berdasarkan pencapaian skor QoL yang dikategorikan sebagai baik (skor 0,69) berdasarkan penelitian sebelumnya, termasuk di Indonesia. ${ }^{9,12}$ Analisis faktor yang berhubungan dengan pancapaian QoL baik dianalisis dengan uji kai kuadrat dan analisis multivariat dengan regresi logistik. Seluruh analisis dilakukan menggunakan SPSS ver. 22 for Windows. Protokol penelitian telah diulas dan disetujui oleh Komite Etik RSU dr. Mohammad Hoesin Palembang. 


\section{Hasil}

Selama periode penelitian terdapat 498 prosedur pemasangan shunt, dengan 95 pasien berusia 5-18 tahun pada saat pengambilan data. Delapan belas pasien meninggal dan 46 tidak dapat dihubungi atau dengan rekam medis yang tidak lengkap sehingga terdapat 31 subjek yang dapat dianalisis (Gambar 1).

Karakteristik subyek tertera pada Tabel 1. Sebagian besar pasien dengan hidrosefalus non-komunikans dan dipasang shunt kurang dari satu bulan setelah diagnosis, meski terdapat kasus dengan pemasangan shunt yang tertunda. Kejang dan komplikasi shunt terjadi pada sejumlah besar pasien.

Skor HOQ keseluruhan sebesar 0,79 (rentang 0,17 sampai 0,97$)$. Skor kognitif merupakan skor terlemah. Hasil analisis univariat untuk menilai perbedaan skor berdasarkan faktor-faktor risiko tertera pada Tabel 2 . Usia saat pemasangan shunt memiliki korelasi negatif sedang dengan skor keseluruhan dan semua sub-skor. Rentang waktu antara pemasangan shunt dan waktu penelitian memiliki korelasi positif sedang dengan skor keseluruhan dan skor sosial-emosional. Meski anak yang dipasang shunt $>1$ bulan setelah diagnosis dan yang mengalami kejang menunjukkan skor HOQ lebih rendah, secara statistik perbedaan skor tidak ditemukan bermakna. Adanya komplikasi shunt berhubungan dengan penurunan bermakna dalam skor keseluruhan dan semua sub-skor. Dilakukan juga analisis berdasarkan pencapaian skor keseluruhan yang baik berdasarkan temuan penelitian sebelumnya, yaitu skor $0,69.7,9,12,13$

Adanya kejang dan komplikasi shunt berhubungan secara bermakna dengan luaran QoL buruk (skor HOQ keseluruhan $\leq 0,69$ ) dengan risiko relatif cukup besar. Akan tetapi, setelah dilakukan analisis multivariat dengan regresi logistik, hanya komplikasi shunt yang ditemukan secara independen dapat memengaruhi luaran dengan p 0,03 dan adjusted OR 15,11 (IK 95\%: $2,45-95,11)$.

\section{Pembahasan}

Hidrosefalus merupakan kelainan bidang bedah saraf yang paling sering dijumpai oleh dokter bedah saraf ataupun dokter anak. Prevalensi di seluruh dunia diperkirakan sebesar 71,9/100.000 anak dan angka kejadiannya di negara berkembang lebih tinggi. ${ }^{14}$

Intervensi bedah termasuk pemasangan VP shunt telah dapat menurunkan mortalitas hidrosefalus secara bermakna. Oleh karena itu, saat ini pengobatan terutama juga ditujukan untuk memperbaiki aspek

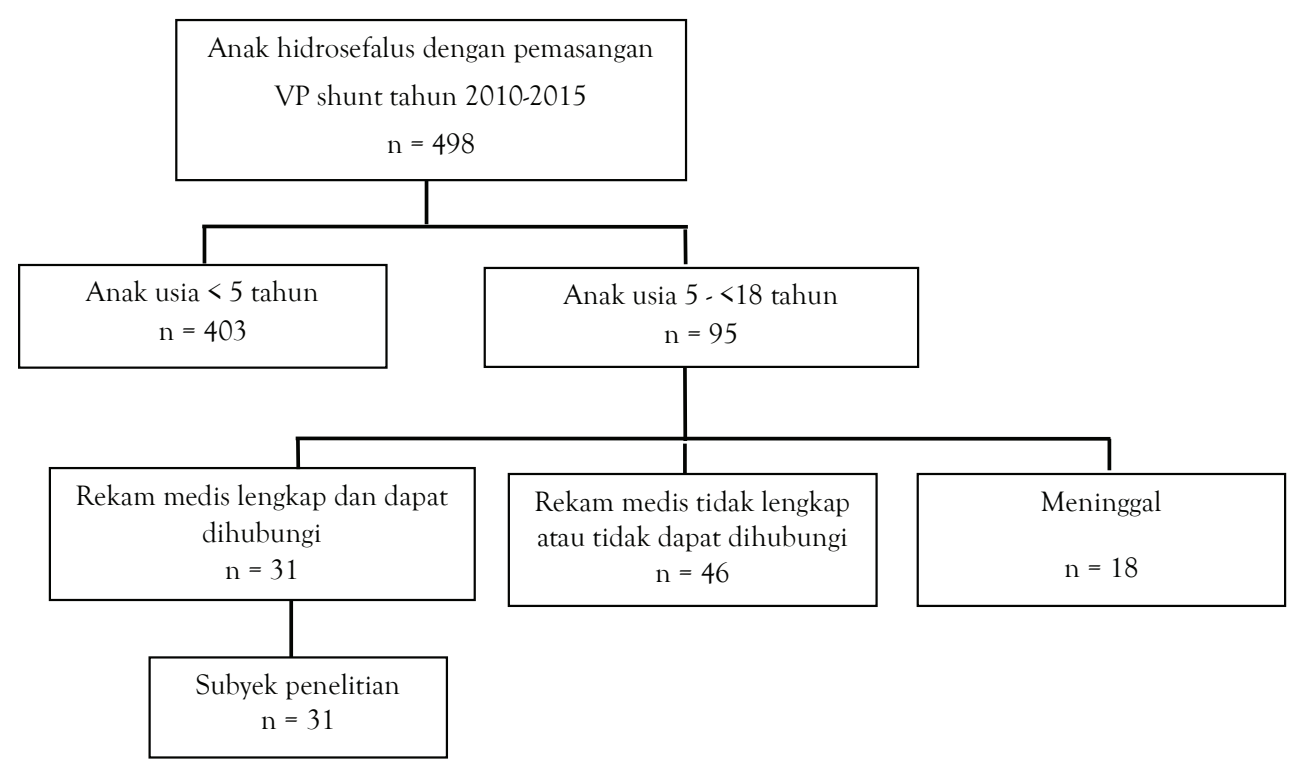

Gambar 1. Diagram pengambilan subjek 
Tabel 1. Karakteristik subyek

\begin{tabular}{lc}
\hline Karakteristik & Frekuensi \\
\hline Kelamin (\%) & $16(51,6)$ \\
$\quad$ Laki-laki & $15(48,4)$ \\
Perempuan & $90(60-204)$ \\
Usia* (bulan) & $61(2-194)$ \\
Usia saat VP shunt* (bulan) & $24(6-143)$ \\
Jangka waktu antara VP shunt dan penelitian* (bulan) & \\
Jenis hidrosefalus (\%) & $6(19,4)$ \\
$\quad$ Komunikans & $25(80,6)$ \\
$\quad$ Non-komunikans & \\
Jangka waktu antara diagnosis dan VP shunt (\%) & $27(87,1)$ \\
Satu bulan atau kurang & $4(12,9)$ \\
$\quad$ Lebih dari satu bulan & \\
Kejang setelah VP shunt $(\%)$ & $10(32.3)$ \\
$\quad$ Kejang & $21(67,7)$ \\
$\quad$ Tidak ada kejang & \\
Komplikasi setelah VP shunt $(\%)$ & $11(35,5)$ \\
Ada komplikasi & $20(64,5)$ \\
Tidak ada komplikasi & \\
Skor HOQ ${ }^{* *}$ & $0,73 \pm 0,25$ \\
Keseluruhan & $0,75 \pm 0,27$ \\
Fisik & $0,78 \pm 0,22$ \\
Sosial-emosional & $0,66 \pm 0,31$ \\
$\quad$ Kognitif & \\
* median (range) ${ }^{* *}$ rerata \pm standard deviasi & \\
&
\end{tabular}

Tabel 2. Analisis univariat perbedaan skor HOQ berdasarkan faktor risiko

\begin{tabular}{|c|c|c|c|c|}
\hline Faktor & Skor keseluruhan & Fisik & Sosial-emosional & Kognitif \\
\hline Usia saat VP shunt & $\begin{array}{l}\mathrm{r}=-0,519 \\
\mathrm{p}=0,003^{*}\end{array}$ & $\begin{array}{l}r=-0,430 \\
p=0,016^{*}\end{array}$ & $\begin{array}{l}\mathrm{r}=-0,519 \\
\mathrm{p}=0,003^{*}\end{array}$ & $\begin{array}{l}\mathrm{r}=-0,526 \\
\mathrm{p}=0,002^{*}\end{array}$ \\
\hline Usia saat penelitian & $\begin{array}{l}\mathrm{r}=-0,300 \\
\mathrm{p}=0,102^{*}\end{array}$ & $\begin{array}{l}\mathrm{r}=-0,226 \\
\mathrm{p}=0,222^{*}\end{array}$ & $\begin{array}{l}\mathrm{r}=-0,318 \\
\mathrm{p}=0,081^{*}\end{array}$ & $\begin{array}{l}r=-0,342 \\
p=0,059^{*}\end{array}$ \\
\hline $\begin{array}{l}\text { Jangka waktu antara VP shunt dan pene- } \\
\text { litian }\end{array}$ & $\begin{array}{c}r=0,382 \\
\mathrm{p}=0,034^{*}\end{array}$ & $\begin{array}{c}\mathrm{r}=0,291 \\
\mathrm{p}=0,111^{*}\end{array}$ & $\begin{array}{c}\mathrm{r}=0,395 \\
\mathrm{p}=0,028^{*}\end{array}$ & $\begin{array}{c}\mathrm{r}=0,321 \\
\mathrm{p}=0,078^{*}\end{array}$ \\
\hline $\begin{array}{l}\text { Jenis hidrosefalus }{ }^{\#} \\
\text { Non-komunikans } \\
\text { Komunikans }\end{array}$ & $\begin{array}{c}0,79(0,17-0,97) \\
0,87(0,18-0,97) \\
\mathrm{p}=0,478^{* *}\end{array}$ & $\begin{array}{c}0,85(0,13-0,98) \\
0,91(0,12-0,98) \\
\mathrm{p}=0,643^{* *}\end{array}$ & $\begin{array}{c}0,85(0,23-0,98) \\
0,91(0,32-0,98) \\
p=0,575^{* *}\end{array}$ & $\begin{array}{c}0,75(0,12-0,97) \\
0,93(0,11-0,97) \\
p=0,291^{* *}\end{array}$ \\
\hline $\begin{array}{l}\text { Jangka waktu antara diagnosis dan VP } \\
\text { shunt } \\
>1 \text { bulan } \\
\leq 1 \text { bulan }\end{array}$ & $\begin{array}{c}0,63(0,23-0,96) \\
0,83(0,17-0,97) \\
p=0,513^{* *}\end{array}$ & $\begin{array}{c}0,58(0,25-0,98) \\
0,86(0,12-0,98) \\
p=0,345^{* *}\end{array}$ & $\begin{array}{c}0,70(0,31-0,97) \\
0,87(0,23-0,98) \\
\mathrm{p}=0,345^{* *}\end{array}$ & $\begin{array}{c}0,61(0,13-0,95) \\
0,77(0,11-0,97) \\
\mathrm{p}=0,755^{* *}\end{array}$ \\
\hline $\begin{array}{l}\text { Kejang setelah VP shunt" } \\
\text { Kejang } \\
\text { Tidak ada kejang }\end{array}$ & $\begin{array}{c}0,65(0,17-0,97) \\
0,85(0,40-0,86) \\
\mathrm{p}=0,186^{* *}\end{array}$ & $\begin{array}{c}0,67(0,12-0,98) \\
0,87(0,32-0,98) \\
\mathrm{p}=0,065^{* *}\end{array}$ & $\begin{array}{c}0,72(0,23-0,98) \\
0,87(0,43-0,98) \\
\mathrm{p}=0,217^{* *}\end{array}$ & $\begin{array}{c}0,41(0,11-0,97) \\
0,79(0,12-0,95) \\
\mathrm{p}=0,348^{* *}\end{array}$ \\
\hline $\begin{array}{l}\text { Komplikasi VP shunt } \\
\text { Ada komplikasi } \\
\text { Tidak ada komplikasi }\end{array}$ & $\begin{array}{c}0,60(0,17-0,96) \\
0,88(0,40-0,97) \\
p=0,014 * *\end{array}$ & $\begin{array}{c}0,60(0,12-0,98) \\
0,89(0,43-0,98) \\
p=0,044^{* *}\end{array}$ & $\begin{array}{c}0,70(0,23-0,97) \\
0,91(0,43-0,98) \\
p=0,018^{* *}\end{array}$ & $\begin{array}{c}0,25(0,11-0,95) \\
0,85(0.27-0,97) \\
\mathrm{p}=0,023^{* *}\end{array}$ \\
\hline
\end{tabular}


Erni Desmita dkk: Faktor yang memengaruhi luaran kualitas hidup anak dengan hidrosefalus setelah pemasangan VP shunt

Tabel 3. Analisis faktor yang memengaruhi pencapaian luaran QoL baik (skor HOQ keseluruhan $>0,69$ ).

\begin{tabular}{lcccc}
\hline \multicolumn{1}{c}{ Faktor } & $\begin{array}{c}\text { Skor keseluruhan } \\
\leq 0,69\end{array}$ & $\begin{array}{c}\text { Skor keseluruhan } \\
>0,69\end{array}$ & RR (95\% CI) & $\mathrm{p}^{*}$ \\
\hline $\begin{array}{l}\text { Jangka waktu antara diagnosis dan VP } \\
\text { shunt (\%, bulan) }\end{array}$ & & & & \\
$\quad 1$ & $2(50,0)$ & $2(50,0)$ & 1,50 & 0,516 \\
$\leq 1$ & $9(33,3)$ & $18(66,7)$ & $(0,49-4,58)$ & \\
Jenis hidrosefalus (\%) & & & \\
$\quad$ Non-komunikans & $9(36,0)$ & $16(64,0)$ & 1,08 & 0,902 \\
$\quad$ Komunikans & $2(33,3)$ & $4(66.7)$ & $(0,77-7,40)$ & \\
Kejang setelah VP shunt (\%) & & & \\
$\quad$ Kejang & $6(60,0)$ & $4(40,0)$ & 2,52 & 0,049 \\
Tidak ada kejang & $5(23,8)$ & $16(76,2)$ & $(1,01-6,31)$ & \\
Komplikasi VP shunt (\%) & & & \\
$\quad$ Ada komplikasi & $8(72,7)$ & $3(27,3)$ & 4,85 & 0,001 \\
$\quad$ Tidak ada komplikasi & $3(15,0)$ & $17(85,0)$ & $(1,61-14,63)$ & \\
\hline * Uji Fishers & & &
\end{tabular}

${ }^{*}$ Uji Fisher's

kualitas hidup (QoL) pasien. Luaran QoL pasien hidrosefalus yang telah dipasang VP shunt ditemukan sangat bervariasi. Penilaian QoL pada anak juga tidak mudah. Hydrocephalus outcome questionnaire (HOQ) dikembangkan sebagai perangkat spesifik untuk menilai luaran fungsional anak hidrosefalus yang telah dipasang VP shunt. Kuesioner ini mudah dilakukan dan berbagai penelitian menunjukkan validitasnya dalam menilai status kesehatan anak hidrosefalus yang terpasang VP shunt. ${ }^{7,13}$

Hasil penelitian ini menunjukkan skor HOQ untuk fisik $0,75 \pm 0,27$, sosial-emosional $0,78 \pm 0,22$, kognitif $0,66 \pm 0,31$ dan skor keseluruhan $0,73 \pm 0,25$. Angka ini lebih baik dari penelitian terdahulu yang umumnya memiliki skor HOQ keseluruhan 0,67-0,69.5,7,9,13 Hal ini kemungkinan dikarenakan perbaikan dari pelayanan kesehatan, tetapi juga mungkin karena pada penelitian ini hidrosefalus akibat penyakit kongenital yang kompleks dieksklusi. Adanya rentang yang lama (median 24 bulan) antara pemasangan VP shunt dan pemeriksaan HOQ pada penelitian ini juga dapat menyebabkan kasus-kasus yang lebih berat tereksklusi karena meninggal, telah diketahui kematian dan komplikasi VP shunt sebagian besar terjadi pada waktuwaktu awal setelah pemasangan. ${ }^{15} \mathrm{Hal}$ ini mungkin yang menyebabkan tingginya mortalitas pasien pada populasi penelitian ini.

Skor kognitif merupakan skor yang paling rendah. Hasil ini serupa dengan -penelitian sebelumnya., Penilaian kognitif dengan HOQ ditemukan memiliki korelasi yang baik dengan pemeriksaan neuropsikologis konvensional, seperti pemeriksaan intelegensi Wechsler. ${ }^{6,13}$ Kejadian IQ borderline atau disabilitas intelektual dilaporkan pada hingga $70 \%$ anak dengan hidrosefalus. Defisit pada hidrosefalus dapat meliputi semua aspek kognitif yaitu eksekutif, memori, visualspasial, dan bahasa. ${ }^{4}$

Bersamaan dengan defisit fungsi fisik dan sosialemosional, gangguan-gangguan ini menyebabkan anak menjadi tergantung orang lain dalam melakukan aktivitas sehari-hari, seperti membersihkan diri dan menggunakan kamar mandi. Juga terdapat gangguan belajar, keterbatasan interaksi dengan teman sebaya dan rendahnya rasa percaya, yang semuanya menjadi masalah yang harus dihadapi orang tua dan penyedia layanan sosial atau kesehatan. ${ }^{16}$

Usia saat pemasangan shunt berkorelasi negatif dengan semua skor HOQ, yang menunjukkan bahwa pemasangan yang lebih dini akan menyebabkan luaran QoL lebih baik. Namun, jarak waktu antara diagnosis dan VP shunt tidak berkorelasi negatif dengan skor HOQ, sedangkan jarak waktu antara VP shunt dan pemeriksaan HOQ menunjukkan korelasi positif yang bermakna dengan beberapa sub-skor (keseluruhan dan sosial-emosional), yang berarti terjadi perbaikan QoL setelah pemasangan shunt. Mengingat pada penelitian ini tidak mengikutkan kasus-kasus dengan anomali kongenital kompleks, maka berdasarkan temuantemuan tadi dapat diinterpretasikan bahwa diagnosis dan intervensi dini menyebabkan luaran QoL lebih 
baik. Adanya keterlambatan diagnosis pada sejumlah besar pasien penelitian ini mungkin yang menyebabkan korelasi yang terlihat jelas. Keterlambatan diagnosis sering ditemukan di negara berkembang yang dapat berpengaruh negatif pada fungsi kognitif, fisik dan fungsi-fungsi lain sehingga dapat menurunkan QoL bahkan hingga setelah operasi. ${ }^{17}$

Kami menemukan komplikasi setelah pemasangan VP shunt berhubungan dengan skor HOQ keseluruhan dan semua sub-skor yang lebih rendah. Komplikasi shunt dapat berupa komplikasi aseptik (non-infeksius) dan infeksius. Komplikasi non-infeksius meliputi penyumbatan, fraktur, penyumbatan dan migrasi shunt, over-drainase serta komplikasi-komplikasi lain. Satu penelitian kohort dengan jumlah subjek besar menunjukkan komplikasi yang membutuhkan operasi ulang terjadi pada $33 \%$ anak dengan VP shunt, ${ }^{18}$ tetapi tergantung kondisi pasien, dapat bervariasi antara $23,8-82,8 \% .{ }^{19}$ Serupa dengan penelitian ini, penelitian terdahulu juga menunjukkan efek negatif komplikasi shunt terhadap luaran QoL, baik komplikasi infeksius ${ }^{7,13}$ maupun komplikasi non-infeksius., ${ }^{7,13,20}$ Komplikasi shunt sering timbul perlahan dengan gejala yang tidak jelas sehingga terlambat didiagnosis dan menyebabkan otak terpapar dengan tekanan intrakranial tinggi yang menyebabkan berbagai kerusakan. ${ }^{2}$ Operasi ulang untuk tatalaksana komplikasi shunt juga telah diketahui merupakan faktor risiko kuat terjadinya komplikasi infeksius lebih lanjut. ${ }^{21,22}$

Adanya kejang pada penelitian ini ditemukan berdampak negatif pada skor HOQ, meski pada analisis multivariat tidak ditemukan dapat berpengaruh secara independen. Kejang dan epilepsi dapat terjadi pada $23-40 \%$ anak dengan hidrosefalus, ${ }^{23,24}$ dengan kemungkinan yang lebih besar untuk tidak berespon baik dengan pengobatan anti kejang. Epilepsi dapat berdampak buruk akibat kejangnya sendiri, pengobatannya dan juga stigma yang diakibatkannya. Satu telaah sistematik menunjukkan anak dengan epilepsi memiliki performa rendah dalam domain kemampuan fisik, psikologis, sosial, akademis dan hubungan keluarga. Anak-anak dengan epilepsi struktural, seperti hidrosefalus memiliki kemampuan lebih rendah dibandingkan jenis epilepsi lain..$^{25,26}$ Sesuai dengan penelitian ini, sebagian besar penelitian sebelumnya menunjukkan bahwa kejang merupakan faktor risiko kuat untuk terjadinya gangguan QoL. 5,7,8,13 Hasil analisis multivariat yang tidak bermakna pada penelitian ini kemungkinan dikarenakan jumlah sampel yang sedikit.

Terdapat beberapa kelemahan pada penelitian ini. Jumlah sampel sedikit sehingga hubungan sebenarnya antara faktor risiko dan luaran QoL mungkin tidak ditemukan. Desain penelitian yang retrospektif dapat menyebabkan berbagai bias. Tidak dilakukan analisis terhadap faktor-faktor seperti kemudahan aksesi layanan kesehatan, termasuk sosial-ekonomi dan jarak antara tempat tinggal dan fasilitas kesehatan. Etiologi epilepsi hanya dikelompokkan menjadi komunikans dan non-komunikans sehingga efek etiologi-etiologi tertentu seperti perdarahan, tumor dan lain-lain tidak dapat ditentukan. Meski demikian, telah dilakukan eksklusi terhadap abnormalitas kongenital kompleks yang berdasarkan penelitian terdahulu menyebabkan luaran paling buruk. ${ }^{10}$ Perdarahan perinatal yang juga berhubungan dengan luaran yang buruk ${ }^{16}$ juga tidak ditemukan pada penelitian ini.

\section{Kesimpulan}

Luaran QoL pada penelitian ini ditemukan lebih baik dibandingkan penelitian-penelitian sebelumnya, tetapi hasil ini dapat dikarenakan seleksi subjek. Hasil skor HOQ masih menunjukkan variabilitas tinggi mulai dari sangat jelek hingga sangat baik. Komplikasi shunt dan kejang merupakan faktor yang berhubungan dengan luaran QoL buruk, tetapi hanya komplikasi shunt yang ditemukan berpengaruh secara independen.

\section{Daftar pustaka}

1. Kahle KT, Kulkarni AV, Limbrick DD, Warf BC. Hydrocephalus in children. Lancet 2016;387:788-99.

2. Hanak BW, Bonow RH, Harris CA, Browd SR. Cerebrospinal fluid shunting complications in children. Pediatr Neurosurg 2017;52:381-400.

3. Vinchon M, Rekate H, Kulkarni AV. Pediatric hydrocephalus outcomes: A review. Fluids Barriers CNS. 2012;9:1. doi: https://doi.org/10.1186/2045-8118-9-18.

4. Zielińska D, Rajtar-Zembaty A, Starowicz-Filip A. Cognitive disorders in children's hydrocephalus. Neurol Neurochir Pol 2017;51:234-9.

5. Kulkarni AV, Drake JM, Rabin D, Dirks PB, Humphreys RP, Rutka JT. Measuring the health status of children with hydrocephalus by using a new outcome measure. J Neurosurg.2004;101(Suppl. 2):141-6. 
6. Kulkarni AV, Donnelly R, Shams I. Comparison of hydrocephalus outcome questionnaire scores to neuropsychological test performance in school-aged children: Clinical article. J Neurosurg Pediatr 2011;8:396-401.

7. Iglesias S, Ros B, Martín Á, Carrasco A, Rius F, Arráez MÁ. Functional outcome in pediatric hydrocephalus: Results of applying the Spanish version of the Hydrocephalus Outcome Questionnaire. J Neurosurg Pediatr 2018;21:224-35.

8. Khan SA, Khan MF, Bakhshi SK, dkk. Quality of life in individuals surgically treated for congenital hydrocephalus during infancy: A single-institution experience. World Neurosurg 2017; 101:247-53.

9. Diyo AR. Luaran anak pasca ventrikulo-peritoneal shunt berdasarkan Hydrocephalus Outcome Questionnare (HOQ) dan hubungannya dengan faktor penyebab di Rumah Sakti Umum Pusat Nasional Cipto Mangunkusumo tahun 2003 - 2012 [tesis]. Jakarta: Program Studi Pendidikan Dokter Spesialis Bedah Saraf - Fakultas Kedokteran Universitas Indonesia,2013.

10. Tervonen J, Leinonen V, Jääskeläinen JE, Koponen S, Huttunen TJ. Rate and risk factors of shunt revision in pediatric hydrocephalus patient - population based study. World Neurosurg 2017;101:615-22.

11. Eloqayli H, Alyousef A. Infantile hydrocephalus: Healthrelated quality of life outcome following ventriculoperitoneal shunt. Open Neurol J 2019;13:50-4.

12. Platenkamp M, Hanlo PW, Fischer K, Gooskens RM. Outcome in pediatric hydrocephalus: A comparison between previously used outcome measures and the hydrocephalus outcome questionnaire. J Neurosurg 2007;107(Suppl 1):2631.

13. Kulkarni AV, Shams I. Quality of life in children with hydrocephalus: Results from the Hospital for Sick Children, Toronto. J Neurosurg. 2007;107(Suppl 5):358-64.

14. Isaacs AM, Riva-Cambrin J, Yavin D, dkk. Age-specific global epidemiology of hydrocephalus: Systematic review, metanalysis and global birth surveillance. PLoS One 2018;13:1-24.

15. Gmeiner M, Wagner H, Zacherl C, dkk. Long-term mortality rates in pediatric hydrocephalus-a retrospective single-center study. Child's Nerv Syst 2017;33:101-9.

16. Szefczyk-Polowczyk L, Mandera M. Functioning of the children with hydrocephalus. Acta Neurol Belg 2020;120:34553.

17. Salvador S, Henriques J, Munguambe M, Vaz RM, Barros $\mathrm{H}$. Hydrocephalus in children less than 1 year of age in northern Mozambique. Surg Neurol Int 2014;5:175. doi:10.4103/2152-7806.146489.

18. Riva-Cambrin J, Kestle JRW, Holubkov R, dkk. Risk factors for shunt malfunction in pediatric hydrocephalus: A multicenter prospective cohort study. J Neurosurg Pediatr 2016;17:382-90.

19. Hasanain AA, Abdullah A, Alsawy MFM, dkk Incidence of and causes for ventriculoperitoneal shunt failure in children younger than 2 years: A systematic review. J Neurol Surg 2019;80:26-33.

20. Prakash P, Dhandapani M, Ghai S, Singh N, Dhandapani S. Quality of life among children who had undergone ventriculoperitoneal shunt surgery. J Pediatr Neurosci 2018;13:189-94.

21. Erps A, Roth J, Constantini S, Lerner-Geva L, Grisaru-Soen G. Risk factors and epidemiology of pediatric ventriculoperitoneal shunt infection. Pediatr Int 2018;60:1056-61.

22. Simon TD, Butler J, Whitlock KB, dkk. Risk factors for first cerebrospinal fluid shunt infection: Findings from a multicenter prospective cohort study. J Pediatr 2014;164:1462-8.

23. Tully HM, Kukull WA, Mueller BA. Clinical and Surgical Factors Associated with Increased Epilepsy Risk in Children with Hydrocephalus. Pediatr Neurol 2016;59:18-22.

24. Schubert-bast S, Berghaus L, Filmann N, Freiman T. Risk and risk factors for epilepsy in shunt-treated children with hydrocephalus. Eur J Paediatr Neurol 2019;23:819-26.

25. Stevanovic D, Tadic I, Novakovic T. Health-related quality of life in children and adolescents with epilepsy: A systematic review. Dalam: Gadze ZP, penyunting. Epilepsy in children - Clinical and Social Aspects. Edisi pertama. Rijeka:InTech; 2011.h.161-86.

26. Handryastuti S, Mangunatmadja I. Risk factors influencing the outcomes of infants with epilepsy. Paediatr Indones 2007;47:202-6. 